\title{
SELEÇÃO DE ESPÉCIES BIOINDICADORAS PARA USO EM BIOENSAIOS DE LIXIVIAÇÃO E PERSISTÊNCIA DE ATRAZINA NO SOLO
}

\author{
ELI DANIELI MARCHESAN* \\ GABRIELI DEDORDI** \\ MICHELANGELO MUZELL TREZZI*** \\ RIBAS ANTONIO VIDAL**** \\ DEBORAH PINHEIRO DICK*****
}

\begin{abstract}
Este experimento teve por objetivo selecionar espécies cultivadas com potencial para utilização como bioindicadoras da presença de atrazina em ensaios de persistência e lixiviação. Adotou-se delineamento inteiramente casualizado, com quatro repetições, em bifatorial $5 \times 6$, sendo o fator A constituído pelas concentrações de atrazina com formulação WG $(0,150,300,600,1200 \mathrm{~g}$ atrazina ha-1) e o fator B pelas espécies bioindicadoras: aveia branca, trigo, quiabo, tomate, ervilha e rabanete. Aplicou-se o herbicida atrazina em préemergência das espécies em solo argiloso. Realizaram-se quatro avaliações de estatura de planta, injúria e no final do experimento foram determinadas as matérias verde e seca das partes aéreas. De forma geral, o experimento permitiu classificar as espécies conforme seu nível de sensibilidade à atrazina: quiabo e ervilha evidenciaram pequena sensibilidade; aveia e trigo revelaram nível intermediário de sensibilidade, enquanto que o tomate e o rabanete apresentaram o mais alto nível de sensibilidade.
\end{abstract}

* Mestre, Programa de Pós-Graduação em Agronomia, Área de Produção Vegetal, Universidade Tecnológica Federal do Paraná, Campus Pato Branco, PR (e-mail: elidanieli_marchesan@yahoo.com.br).

** Graduanda, curso de Agronomia, UTFPR, Campus Pato Branco, PR (e-mail: gaby_dedordi@hotmail.com).

*** Professor, Programa de Pós-Graduação em Agronomia, UTFPR, Campus Pato Branco, PR (e-mail: trezzi@utfpr. edu.br).

**** Professor, Departamento de Plantas Daninhas, Universidade Federal do Rio Grande do Sul, (UFRGS), Porto Alegre, RS (e-mail: ribas.vidal@gmail.com).

***** Professora, UFRGS, Porto Alegre, RS (e-mail: debby.dick@gmail.com). 


\section{INTRODUÇÃO}

Os herbicidas representam o principal método para o controle de plantas daninhas em função de suas características de rapidez e praticidade na aplicação, elevada eficiência sobre espécies de difícil controle e baixo emprego de mão-de-obra, entre outros. Os governos de alguns países incentivam o uso de herbicidas oferecendo ao produtor subsídios para sua aquisição (REPETTO, 1985). No entanto, o uso intensivo de herbicidas, inseticidas e fertilizantes pode gerar contaminação ambiental. Os processos de lixiviação, volatilização e escorrimento superficial frequentemente estão associados à contaminação do ambiente por herbicidas. A persistência de herbicidas no solo também causa contaminação ambiental, pois poderá gerar efeitos de intoxicação de culturas em sequência.

A atrazina (2-cloro-4-etilamino-6-isopropilamino-s-triazina) pertence à família das s-triazinas (CORREIA et al., 2007). Em culturas de lavoura, frutíferas, olerícolas e espécies arbóreas e arbustivas usam-se triazinas, grupo que controla plantas daninhas dicotiledôneas e gramíneas em pré-emergência e em pós-emergência inicial. Atrazina é muito utilizada nas culturas de milho e cana-de-açúcar, sendo também indicada para as culturas de abacaxi (Ananas comosus), pinus (Pinus elliottii), seringueira (Hevea brasiliensis), sisal (Agave sisalana) e sorgo (Sorghum spp.) (AGROFIT, 2011).

Pelo fato de impedir a fotossíntese mediante inibição da reação de Hill, a atrazina provoca clorose e necrose foliar. Um efeito secundário causado pela ação fotossintética é a inibição do crescimento (FLECK e VIDAL, 2001).

A atrazina está entre os diferentes agrotóxicos potencialmente impactantes ao ambiente. Há inúmeros relatos de casos de contaminação de lençois freáticos pelo herbicida atrazina, principalmente na América do Norte e Europa (ÁVILA, LEITE e DICK, 2009). No Brasil, são informados na literatura casos de contaminação de águas superficiais e subterrâneas com esse herbicida (PESSOA et al., 2003; CERDEIRA et al., 2005). A atrazina, classificada como moderadamente persistente, pode contaminar a água e alimentos. Conhecer o destino dos resíduos da atrazina em águas e solos assume importância, devido ao efeito fitotóxico provocado em algumas culturas subsequentes à sua aplicação (DELMONTE et al., 1996).

A persistência e fitotoxicidade de atrazina $\left(3,0\right.$ e 6,0 $\left.\mathrm{Kg} \mathrm{ha}^{-1}\right)$ aplicada na cultura do milho sobre girassol semeado em sucessão foram avaliadas por Brighenti et al. (2002). Verificaram que a produtividade da cultura do girassol sofreu reduções significativas em função dos resíduos desse herbicida na semeadura, realizada aos 60 dias após a aplicação. Delmonte et al. (1996) avaliaram a persistência de diferentes doses de atrazina em solos do Sudoeste da Província de Buenos Aires (Argentina) por meio de bioensaio com aveia (Avena sativa Linnaeus) e observaram redução da persistência de atrazina em solos com menor índice de matéria orgânica.

Para analisar o comportamento de agrotóxicos no ambiente, especificamente a persistência e a lixiviação, podem ser empregados métodos simples que demandam pouco investimento em equipamentos e recursos, ou métodos sofisticados que, em geral, necessitam investimentos para compra de equipamentos caros, reagentes, etc. O bioensaio constitui o método mais simples para identificação de solos contaminados por herbicidas, no qual plantas comprovadamente sensíveis aos herbicidas (bioindicadoras) são cultivadas em solo previamente contaminado. Métodos como os químico-analíticos envolvem a cromatografia a líquido (LC) e a gás (GC) e a utilização de herbicidas radiomarcados que, no entanto, são procedimentos sofisticados e, portanto, de maior custo (SILVA, VIVIAN e OLIVEIRA Jr, 2007).

Bioensaio com plantas são capazes de fornecer respostas eficientes, porém menos rápidas do que as técnicas cromatográficas, devido à necessidade de se obter a biodisponibilidade mediante curvas de calibração. Outro aspecto positivo da utilização de biensaios com plantas para 
detecção de herbicidas no solo é que as plantas utilizadas respondem aos níveis de herbicida presentes na solução do solo, simulando a condição mais próxima da situação real verificada a campo.

O presente trabalho teve por objetivo selecionar espécies cultivadas como bioindicadoras da presença do herbicida atrazina para seu uso em bioensaios de lixiviação e persistência desse herbicida.

\section{MATERIAL E MÉTODOS}

O bioensaio para seleção de espécie indicadora de níveis de atrazina no solo foi realizado nos meses de maio e junho de 2009, em casa de vegetação da Universidade Tecnológica Federal

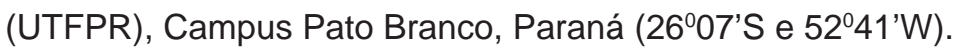

O solo utilizado para o bioensaio foi coletado na Área Experimental da UTFPR, Campus Pato Branco, e peneirado (peneira malha $6 \mathrm{~mm}$ ) para retirada da palha e cascalhos, entre outros materiais mais grosseiros, sendo depositado em vasos com dimensões de $0,1 \mathrm{~m}$ (diâmetro superior) x 0,075 m (altura) x 0,075 m (diâmetro inferior).

Utilizou-se delineamento inteiramente casualizado, com quatro repetições em bifatorial 5 $x 6$, sendo o fator A constituído pelas concentrações de atrazina com formulação WG ( $0,150,300$, 600, $1200 \mathrm{~g}_{\text {atrazina }} \mathrm{ha}^{-1}$ ) e o fator B pelas espécies bioindicadoras: Avena sativa L. (aveia branca), Triticum aestivum L. (trigo), Abelmoschus esculentus (quiabo), Solanum lycopersicum (tomate), Pisum sativum L. (ervilha) e Raphanus sativus L. (rabanete). Para cada espécie foram colocadas seis sementes por vaso à profundidade de $1 \mathrm{a} 2 \mathrm{~cm}$. Aspergiu-se o herbicida no solo úmido, após a semeadura das espécies, com pulverizador costal pressurizado com $\mathrm{CO}_{2}$, mantido à pressão constante e munido de bicos tipo leque, distanciados entre si de $0,50 \mathrm{~m}$ em barra com 1,5 m de largura, totalizando volume de calda aspergida de $200 \mathrm{~L} \mathrm{ha}^{-1}$.

Foram realizadas avaliações de toxicidade e estatura das plantas aos 14, 21, 28 e 35 dias após a aplicação (DAA) das doses de atrazina e das massas de planta verde e seca ao final do experimento aos 35 DAA. Para determinar sua toxicidade às plantas foram atribuídas notas que variaram de 0\% para a ausência de efeito (atrofia, encarquilhamento, necrose, clorose) a 100\% para efeito letal às plantas, conforme metodologia descrita por Frans et al. (1986), não incluindo a inibição de germinação. A estatura foi determinada com régua milimétrica, tomando-se como referência a base da planta rente ao solo até a última folha. Avaliou-se a massa de planta verde pela pesagem da parte aérea das plantas, após seu corte rente à superfície do solo e retirada dos vasos. A parte aérea das plantas foi seca em estufa a $60^{\circ} \mathrm{C}$ até se atingir massa constante para determinação da massa de planta seca.

Procedeu-se a análise da variância dos resultados pelo teste $F$ a $5 \%$ de probabilidade de erro experimental, com auxílio do programa estatístico WINSTAT( MACHADO e CONCEIÇÃO, 2005). As médias de variáveis qualitativas foram comparadas pelo teste DMS e a relação entre níveis de fator quantitativo e variáveis resposta ajustada por regressão polinomial (STEEL e TORRIE,1980).

\section{RESULTADOS E DISCUSSÃO}

Para a variável fitotoxicidade verificou-se significância da interação entre os fatores avaliados (doses e espécie). Na primeira avaliação efetuada aos 14 DAA destacou-se a toxicidade ao tomate e a toxicidade intermediária para quiabo, trigo, rabanete e aveia (Figura 1 A). Aos 21, 28 e 35 DAA, a espécie mais sensível ao herbicida atrazina foi o rabanete (Figura $1 \mathrm{~B}, \mathrm{C}, \mathrm{D}$ ).

Para todas as espécies, com exceção da ervilha, a toxicidade mais pronunciada foi encontrada nos níveis de 600 e $1200 \mathrm{~g}$ atrazina ha-1. A ervilha apresentou a maior tolerância à 
atrazina dentre as espécies avaliadas, pois os níveis de toxicidade causados pelo herbicida atingiram o máximo de $25 \%$ na avaliação efetuada aos 21 DAA. Nas demais avaliações, os valores foram inferiores a $10 \%$ (Figura 1).

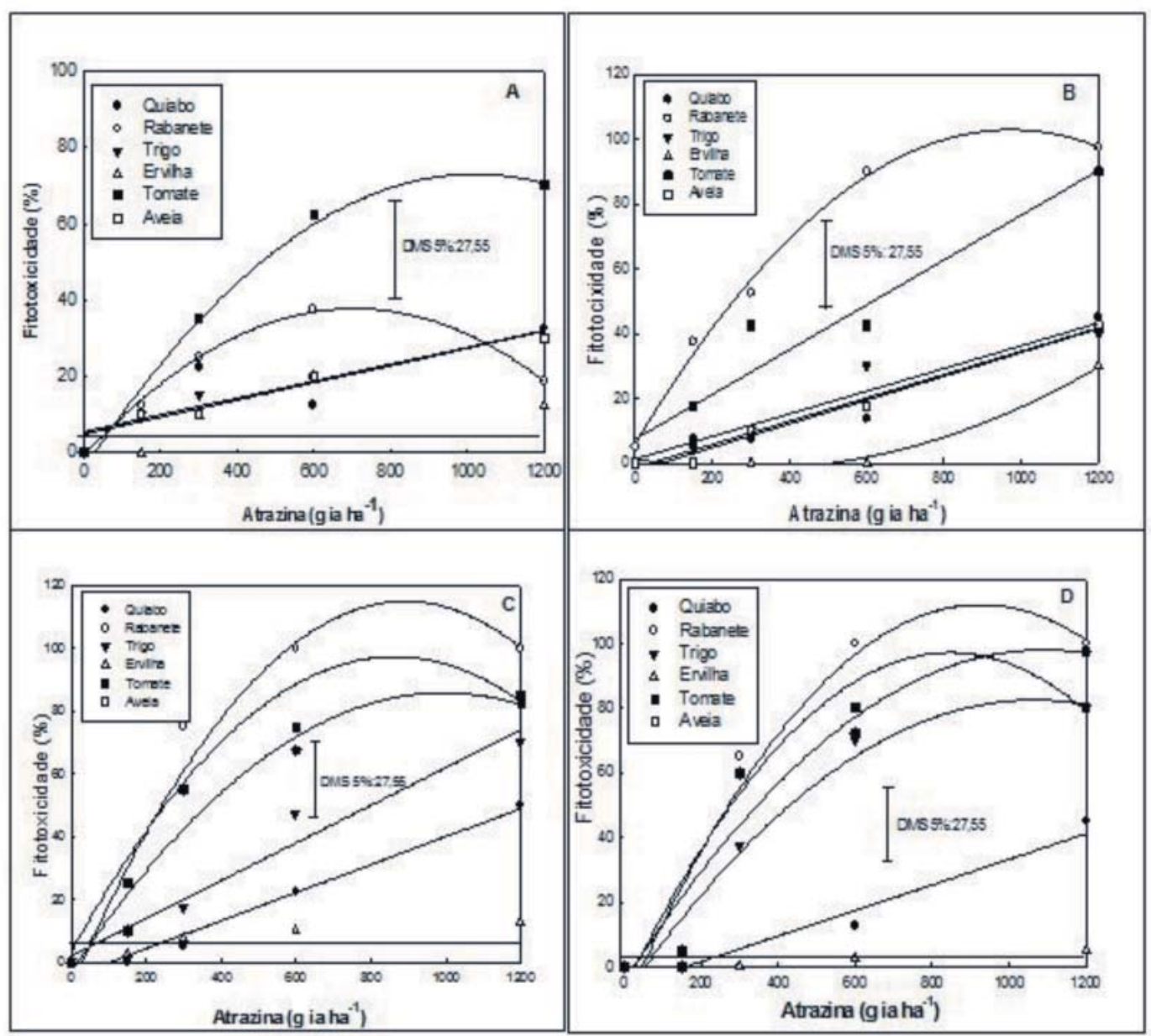

\section{FIGURA 1 - FITOTOXICIDADE ÀS PLANTAS AOS 14(A), 21(B), 28(C) E 35(D) DIAS APÓS A APLICAÇÃO DE DIFERENTES NÍVEIS DE ATRAZINA - UTFPR, PATO BRANCO/2009}

As diferenças de toxicidade entre as espécies variaram de acordo com a dose de herbicida e com o período de avaliação. Aos 14 DAA até a dose de $150 \mathrm{~g}$ atrazina ha-1 não foram observadas diferenças significativas de toxicidade entre as espécies. A partir da avaliação aos 21 DAA foram detectadas diferenças entre as espécies com a utilização da dose de $150 \mathrm{~g}$ de atrazina ha-1. $\mathrm{Em}$ ordem decrescente, rabanete, tomate e aveia foram as espécies que apresentaram os maiores níveis de toxicidade por atrazina. Aos 35 DAA distinguiram-se dois grupos quanto à fitotoxicidade. O grupo com maior fitotoxicidade devido à presença de atrazina foi composto por rabanete, tomate, aveia e trigo. Embora a ervilha e o quiabo tenham se distinguido das demais espécies pelos menores índices de fitotoxicidade, os níveis de toxicidade ao quiabo atingiram valores superiores a $40 \%$ nas doses mais elevadas de atrazina.

Para a variável estatura de planta, normalizada em relação à testemunha, houve significância da interação entre os fatores avaliados. Em geral, observou-se redução da estatura das plantas em função do incremento nos níveis de atrazina depositados no solo (Figura 2). 

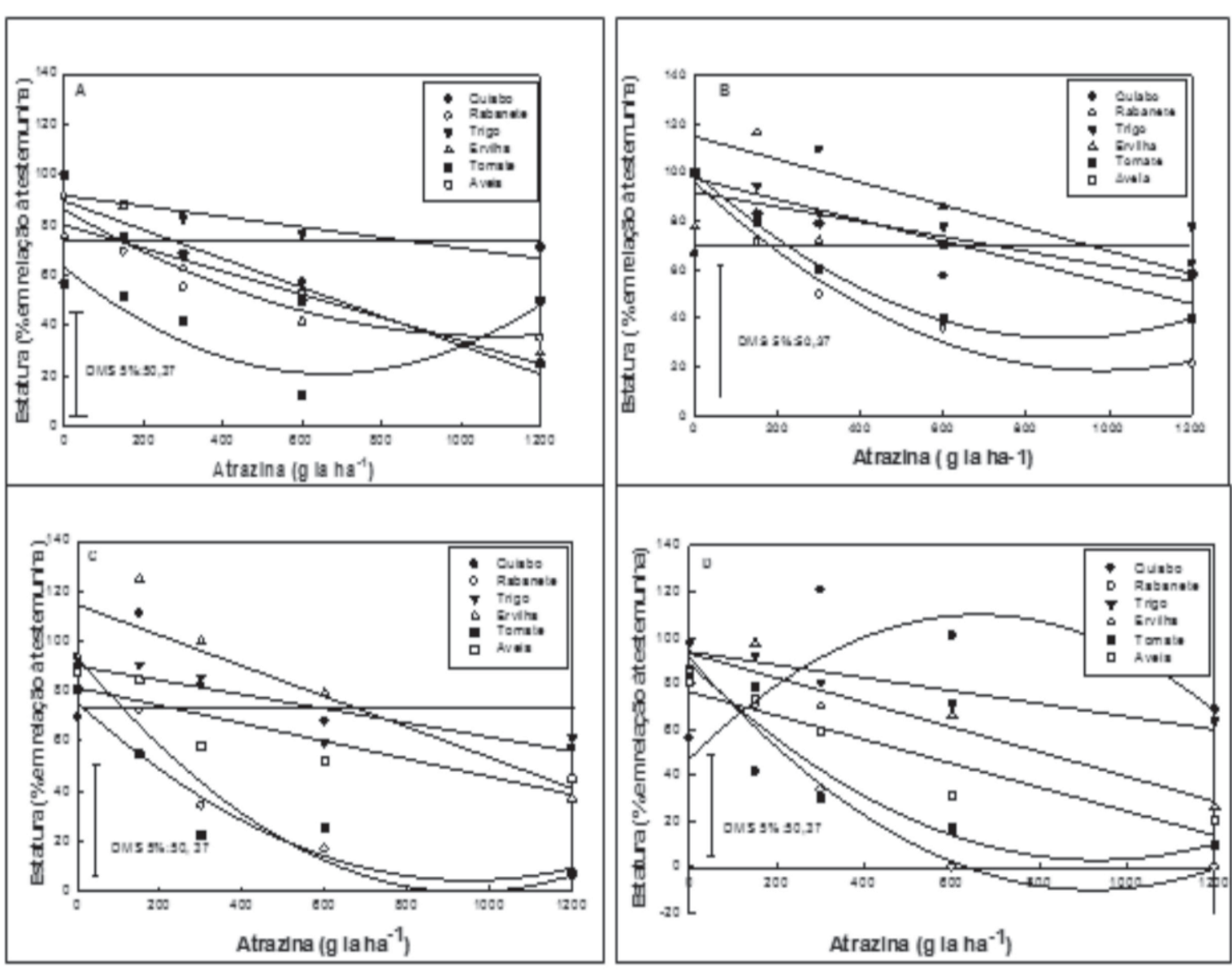

\section{FIGURA 2 - ESTATURA DE PLANTA AOS 7(A), 14(B), 21(C) E 28(D) DIAS APÓS A APLICAÇÃO (DAA) DE DIFERENTES NÍVEIS DE ATRAZINA - UTFPR, PATO BRANCO/2009}

O ranqueamento das espécies com relação à resposta de estatura à atrazina indicou que o tomate (7 DAA) e o rabanete (14, 21 e 28 DAA) foram as espécies mais sensíveis aos menores níveis de atrazina e que apresentaram maior redução da estatura com a utilização de níveis mais elevados (Figura 2 a, b , c , d). A ervilha e o quiabo foram as espécies menos sensíveis (Figura 2).

Nas avaliações efetuadas aos 7, 14 e 21 DAA, a estatura de quiabo não demonstrou resposta aos diferentes níveis de atrazina e aos 28 DAA a resposta ajustou-se ao modelo quadrático, em que o nível de $600 \mathrm{~g}$ atrazina ha-1 foi responsável pelo maior valor.

As diferenças de altura de planta entre as espécies avaliadas foram modificadas com o decorrer das avaliações em razão da maior sensibilidade inicial de algumas espécies à atrazina do que outras (Figura 2). Tal fato se explica porque que as taxas de metabolização do herbicida são mais pronunciadas em determinadas espécies, principalmente em estádios iniciais. No entanto, é possível que a atividade das enzimas metabolizadoras não seja suficiente para evitar que o efeito tóxico de atrazina se intensifique com o decorrer do tempo, especialmente nos níveis mais elevados, o que provoca redução das diferenças entre as espécies. Isso pode ser ilustrado pela maior sensibilidade do rabanete e do tomate em relação às demais espécies, bem caracterizada na avaliação efetuada aos 21 DAA, verificando-se maior similaridade dessas espécies com ervilha e aveia na avaliação efetuada aos 28 DAA (Figura 2 c, d).

Para as variáveis massa das plantas verde e seca, normalizadas em relação ao controle 
e avaliadas aos 35 DAS, também houve significância estatística para a interação entre doses e espécie. Dentre todas as espécies testadas, o quiabo alcançou maiores valores de massa de planta verde, diferindo das demais (Figura 3). A massa verde de quiabo ajustou-se ao modelo quadrático, bastante similar ao comportamento da estatura aos 28 DAA. As massas verdes das demais espécies testadas não apresentaram diferença significativa entre si, mas demonstraram reduções com o aumento da concentração de atrazina (Figura 3).
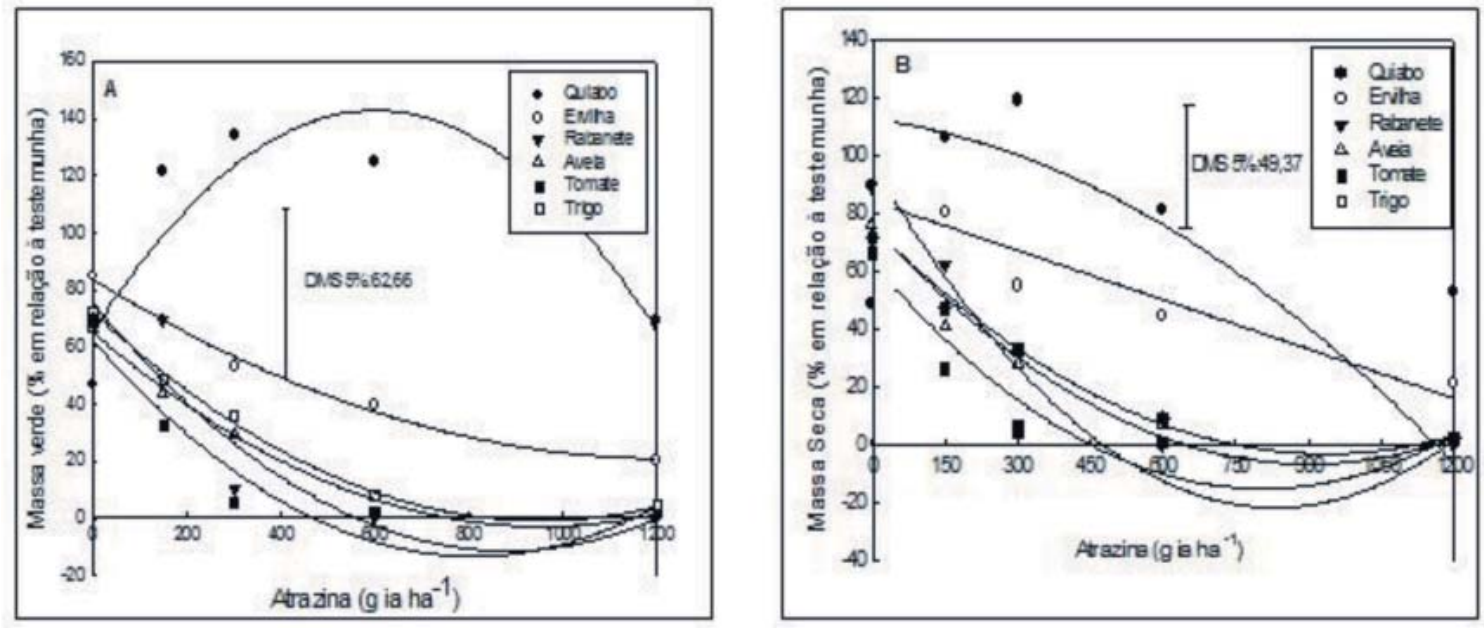

\section{FIGURA 3 - MASSA VERDE (A) E MASSA SECA (B) DAS ESPÉCIES AOS 35 DIAS APÓS A APLICAÇÃO DE ATRAZINA - UTFPR, PATO BRANCO/2009}

O quiabo e a ervilha destacaram-se pelos maiores valores de massa seca, dentre as espécies avaliadas. A massa seca do quiabo somente superou a da ervilha na concentração de $300 \mathrm{~g}_{\text {ia }} \mathrm{ha}^{-1}$. O tomate e o rabanete foram as espécies que demonstraram maior redução da massa seca desde as menores concentrações de atrazina (150 e $300 \mathrm{~g}_{\text {ia ha }}{ }^{-1}$ ). A aveia e o trigo formaram grupo com redução menos drástica da matéria seca conforme a elevação dos níveis de atrazina (Figura 3).

A aveia tem sido empregada como espécie bioindicadora do herbicida atrazina. Para Nunes e Vidal (2009), a elevação das doses de atrazina aumenta os níveis de toxicidade e de reduções da estatura e área foliar das plantas de aveia branca. Atrazina, imazaquin e metribuzin causam fitotoxicidade e estagnação da estatura de aveia branca, bem como cloransulam e s-metolacloro aplicados em pré-emergência (NUNES, 2007). O peso da matéria seca de aveia foi avaliado nos solos de Balcarce, A. Gonzáles Chaves e San Cayetano, localizados na região Sudoeste da Argentina, aos 42, 105, 160 e 223 dias após a aplicação de atrazina. Foi constatada redução da matéria seca mais intensa com a utilização da maior dose e na primeira avaliação (DELMONTE et al., 1996).

Aladesnwa (2005) avaliou a atividade residual do herbicida atrazina sobre o desenvolvimento do quiabo com dose de $3 \mathrm{~kg}_{\text {ia ha-1}}$, superior à utilizada no presente experimento. Verificou que essa espécie não deve ser semeada após a cultura do milho, quando a atrazina foi utilizada, de modo a evitar lesões na cultura e redução na produtividade.

Considerando todas as variáveis avaliadas pode-se afirmar que a fitotoxicidade e a estatura foram mais discriminadoras da resposta das espécies ao efeito de atrazina do que as matérias verde e seca. Além disso, a fitotoxicidade e a estatura foram avaliadas em períodos diferentes. Isso permite a escolha da época mais adequada para determinação desses parâmetros em caso de ajuste de curvas de calibração, posteriormente utilizadas para quantificar os níveis de atrazina presentes em experimentos de lixiviação e persistência. 


\section{CONCLUSÃO}

De forma geral, o experimento permitiu classificar as espécies conforme seu nível de sensibilidade à atrazina. $\mathrm{O}$ quiabo e a ervilha evidenciaram pequena sensibilidade, a aveia e o trigo enquadraram-se no nível intermediário de sensibilidade, enquanto que o tomate e o rabanete apresentaram o mais alto nível de sensibilidade.

\section{ABSTRACT \\ SELECTION OF BIOINDICATORS FOR USE ON LEACHING AND PERSISTENCE OF ATRAZINE IN SOIL BIOASSAYS}

The present work aimed to select cultivated species with potential to act as bioindicators of atrazine presence on persistence leaching assays. The experiment was conducted at a completely randomized design with four replications in a factorial scheme $5 \times 6$, being the A factor consisted of atrazine concentrations WG formulatios $\left(0,150,300,600\right.$, atrazine $\left.1200 \mathrm{~g} \mathrm{ha}^{-1}\right)$ and B factor by bioindicators species: oat, wheat, okra, tomatoes, peas and radish. The herbicide was applied in pre emergence of the species in a clay soil. It were performed four evaluations of plant stature and injury and at the end were evaluated fresh and dry matter of the shoots. Overall, the experiment allowed to classify the species according to their level of sensitivity to atrazine: okra and peas showed little sensitivity, oats and wheat had an intermediate sensitivity, while the tomato and radish had the highest sensitivity level.

KEY-WORDS: ATRAZINE; BIOINDICATOR SPECIES; BIOASSAY; LEACHING; PERSISTENCE.

\section{REFERÊNCIAS}

1 AGROFIT. Sistema de Agrotóxicos Fitossanitários. Ingrediente ativo - atrazina. Disponível em: http://agrofit.agricultura. gov.br/agrofit_cons/principal_agrofit_cons. Acesso em: 16 jan. 2011.

2 ALADESNWA, R. D. Screenhouse evaluation of atrazine for soil residual activity on growth, development and nutritional quality of okra (Abelmoschus esculentus Moench) in southwestern Nigeria. Science Direct, v. 24, p. 927-931, 2005.

3 ÁVILA, L. G.; LEITE, S. B.; DICK, D. P. Formulações de atrazina em xerogéis: síntese e caracterização. Química Nova, São Paulo, v.32, n.7, p. 1727-1733, 2009.

4 BRIGHENTI, A. M. et al. Persistência e fitotoxicidade o herbicida atrazina aplicado na cultura do milho sobre a cultura do girassol em sucessão. Planta Daninha, Viçosa, v.20, n.2, p.291-297, 2002.

5 CERDEIRA, A. L. et al. Lixiviação de atrazina em solo em área de recarga do aquífero guarani. Revista Brasileira de Herbicidas, Passo Fundo, v. 4, n.1, p. 99-101, 2005.

6 CORREIA, F. V. et al. Adsorção de atrazina em solo tropical sob plantio direto e convencional. Pesticidas: revista de ecotoxicologia e meio ambiente, Curitiba, v. 17, p.37- 46, 2007.

7 DELMONTE, A. A et al. Persistence of the biocide activity of atrazine in soils of the southeast of Buenos Aires Province. Planta Daninha, Viçosa, v. 14, n. 2, p. 110 - 117,1996.

8 FLECK, N.G.; VIDAL, R.A. Inibidores do fotossistema II. In: VIDAL, R.A.; MEROTTO Jr., A. (eds.). Herbicidologia. Porto Alegre: Evangraf, 2001. p. 100-122.

9 FRANS, R. et al. Experimental design and techniques for measuring and analyzing plant responses to weed control practices. In: CAMPER, N. D. Research methods in weed science. Champaign: Weed Science, 1986. p. 29-46.

10 MACHADO, A. A.; CONCEIÇÃO, A.R. WinStat - sistema de análise estatística para Windows. Versão Beta. Pelotas: Universidade Federal de Pelotas, 2005. (Software).

11 NUNES, A. L. Persistência e lixiviação dos herbicidas residuais s-metolachlor e imazaquin associados ao paraquat ou glyphosate. 2007. 93 f. Dissertação (Mestrado em Fitotecnia) - Universidade Federal do Rio Grande do Sul, Porto Alegre, 2007.

12 NUNES, A. L.; VIDAL, R. A. Seleção de plantas quantificadoras de herbicidas residuais. Pesticidas: revista de ecotoxicologia e meio ambiente, Curitiba, v.19, p. 19 - 28, 2009.

13 PESSOA, M. C. P. Y. et al. Identificação de áreas de exposição ao risco de contaminação de águas subterrâneas pelos 
herbicidas atrazina, diuron e tebutiuron. Pesticidas: revista ecotoxicologia e meio ambiente, Curitiba, v.13, p.111-122, 2003.

14 REPETTO, R. Paying the price: pesticide subsidies in developing countries. Washington, Dc: World Resources Institute, 1985. p.40.

15 SILVA, A.; VIVAN, R.; OLIVEIRA Jr, R. Herbicidas: comportamento no solo. In: SILVA, A. A.; SILVA, J. F. Tópicos em manejo integrado de plantas daninhas. Viçosa: UFV, 2007. p. 155-209.

16 STEEL, R.G.D.; TORRIE, J.H. Principles and procedures of statistics: a biometrical approach. $2^{\text {nd }}$ ed. New York: McGraw-Hill, 1980. p. 63. 